\title{
Electromagnetic acoustic boiler tubes inspection with robotic device
}

\author{
Anatoli Vakhguelt ${ }^{1}$, Riady Syswoio Jo ${ }^{2}$, Marek J. Bergander ${ }^{3}$ \\ ${ }^{1}$ Nazarbayev University, Astana, Kazakhstan \\ ${ }^{2}$ Swinburne University of Technology, Kuching, Malaysia \\ ${ }^{3}$ Magnetic Development, Inc., Madison, CT, USA \\ ${ }^{1}$ Corresponding author \\ E-mail: ${ }^{1}$ anatoli.vakhguelt@nu.edu.kz, ${ }^{2}$ rsiswoyo@swinburne.edu.my, ${ }^{3}$ mjb1000@aol.com
}

Received 3 November 2017; accepted 23 November 2017

DOI https://doi.org/10.21595/vp.2017.19453

Check for updates

\begin{abstract}
This paper dedicated to electromagnetic acoustic (EMA) inspection of boiler tubes in the process of regular maintenance for prevention of tube rupture. This non-destructive testing method is developed to replace commonly used ultrasonic method of inspection which is costly and very labor intensive. During proposed EMA inspection surface of tubes does not require sandblasting and special coupling between measuring tool and tube wall. Commonly used ultrasonic method, based on detection of the wave generated by a piezoelectric effect of a crystal transducer, provides accurate but sparse data and takes long time to inspect healthy boiler condition. Electromagnetic acoustic transducer EMAT generates such wave directly in tube material by electromagnetic method. EMAT technology is well known and used in many nondestructive testing situations. This method relies on generating ultrasound wave directly in the metal in the form of elastic wave with ultrasonic velocity, characteristic for a given metal. There are two ways that EMATs can generate elastic energy directly in the boiler water-wall. The first is via the "Lorentz force" mechanism where interaction between an applied magnetic field and induced eddy currents produces an elastic wave. The second is through magnetostriction (MS), where an alternating magnetic field generates an alternating elastic force. Developed and fabricated with high energy Neodymium-Iron-Boron permanent magnets with magnetic energy over $56 \mathrm{MGsOe}$ by M. Bergander [1] transducer is able to generate strong elastic wave using magnitostrictive properties of tube material for prediction of the tube thickness. In the special conditions of coal-fired boiler inside and outside surfaces of the tube are covered by erosive and corrosive layers. Those corrosive and erosive layers have good magnitostrictive properties which allow making water-wall thickness measurement without sand blasting and without necessity to have coupling between measurement tool and the tube material surface. This method allows inspecting boiler tubing much faster with the high quality of assessment. To make process of inspection faster claiming robot has been designed. This robot is able to deliver sensor of the measuring device to the surface of the tube and provide stable data reading. Using such robotic device it is possible to do automation of the inspection procedure.
\end{abstract}

Keywords: ultrasonic testing, EMAT, boilers, tube thickness, claiming robot.

\section{Introduction}

This work has been done for the development of a non-destructive testing (NDT) method that will improve the reliability of coal-fired boilers by reducing down-time related to corrosive and erosive failure of the water-wall tubes. The method is intended to minimize operating costs by reducing the number of unscheduled plant shut-downs. Our approach is based upon developing improvements to the ultrasonic NDT methods and procedures that are commonly employed in the routine NDT of these structures and to how the information from these measurements is used to predict the remaining safe operating life of these structures. Specifically, the test system based on EMAT (electromagnetic acoustic transducer) is being developed and adapted to local Kazakhstan industrial conditions. This work is made possible by recent advances in magnetic materials, electronics, computer modelling and robotics. 


\section{EMAT technology development}

There are two ways that EMATs can be used for generating elastic energy directly in the boiler water-wall. The first is via the Lorentz force mechanism where interaction between an applied magnetic field and induced (Eddy) currents produces an elastic driving force, usually at the Eddy current frequency [2-4]. The second is through magnetostriction (MS), which is a magneto-elastic phenomenon where an alternating magnetic field generates an alternating elastic force, usually at the alternating field frequency $[1,2,5,6]$. The Lorentz force mechanism has been demonstrated to work well on boiler tubes but, Lorentz force EMAT systems are heavier and costlier than their magnetostrictive (MS) counterparts. Grades of steel commonly used for water-walls has initially low inherent MS. However, when it is exposed to conditions commonly encountered in the fire box of coal-fired boilers (temperatures and pressures), a tightly bonded scale having a large MS coefficient is formed. Elastic waves generated via this MS require very little excitation power and can result in very accurate thickness measurements. However, this MS scale is not formed uniformly throughout the fire box, so accurate thickness measurements cannot be obtained in all important regions of the water-wall. Additionally, the MS coefficient that determines the strength of elastic wave signals can vary dramatically with location within the fire box. In theory, this issue can be managed through proper design of the instrumentation; however, these features have never been designed into a commercial MS-EMAT thickness instrument. In the process of work special transducers were designed and fabricated with high energy Neodymium-Iron-Boron permanent magnets with magnetic energy over $56 \mathrm{MGsOe}$. These transducers were used for laboratory experiments. The results of these experiments have proven the possibility to assess water-wall thickness of the tubes samples obtained at different power plants. The major damage mechanisms were found to be erosion and corrosion of the tubes as well as overheating. Specialized ultrasonic method for detecting the degree of overheating in boiler tubes by measuring the thickness of internal oxide scale was selected. Further work with ultrasonic instrumentation Sonatest had resulted in adopting the optimum transducers and software to conditions most prevalent in Kazakhstan. Electronic circuitry especially designed for EMAT transducers was designed and adopted by the ultrasonic instrumentation "Sonatest" in their new model of instrument MS335. This instrumentation has allowed to develop new method for Remaining Life Assessment of boiler tubes. This method was used for study of a combined effect of both corrosion/wall thinning and overheating. For evaluating degree of overheating it was necessary to know the value of internal and external oxide thickness. These layers are also layers which contribute to the magnetostrictive properties of the material of tubes. At the same time knowledge of these values would allow to predict change of tube material properties which can lead to rupture of the tubes. This would consequently be useful for Remaining Life Assessment. It is clear that due to harsh conditions in the fire-box of boiler oxide layers on both surfaces of tube are growing. That thick layers are decreasing heat conduction properties through the tube and to keep generation of energy on the same level the temperature in the fire-box is raised. In real process in the boilers that is the mechanism of overheating happening often. In the last several years, many power plants throughout the world have gradually improved their ability to predict overheating failures of boiler tubes. Due to recent developments, this improved prediction ability has been based, in part, upon an accurate knowledge of the thickness of a thin layer of thermally-insulating material on the inside of boiler tubing in general and in the boiler water-wall in particular. EMAT transducers can work with general-purpose ultrasonic instruments with certain modifications, most important being the adequate initial pulse, at least $400 \mathrm{~V}$. EMAT transducer used in our experiments was coupled with a standard off-shelf UT equipment "SONATEST" Masterscan 335 and we have done the manual inspection on samples taken from boiler tubes. Our experiments have shown that use of such instrumentation is suitable to measure tube wall thickness as well as thickness of internal oxide layer. 


\section{Laboratory water-wall thickness measurements}

The experiments were done in laboratory using real tube samples obtained from power plants in Kazakhstan. These samples were exposed to real life conditions in boilers. The high temperatures, over $400-450{ }^{\circ} \mathrm{C}$ in the boiler causes the reaction between steel tube material and steam and flue gas producing hard, adhering scale with high contents of iron oxides. The scale is first produced on tube external surface, directly exposed to the flame, where temperatures are highest. For the purpose of obtaining magnetostrictive coupling between EMAT transducer and the tube it is not, however critical where the scale is located. Good indications were obtained with scale on either surface while testing from the outside. More important than location is the chemical composition of the scale, determining its magnetostrictive properties and its adherence to the parent metal. The scale thickness, even so emphasized in many previous publications was found not to be that important as authors were able to obtain good EMAT indications through scale ranging from less than few microns to $7 \mathrm{~mm}$ thick [7]. Figure 1 shows the EMAT transducer coupled with a standard off-shelf UT equipment and how the manual inspection is done on boiler tubes.
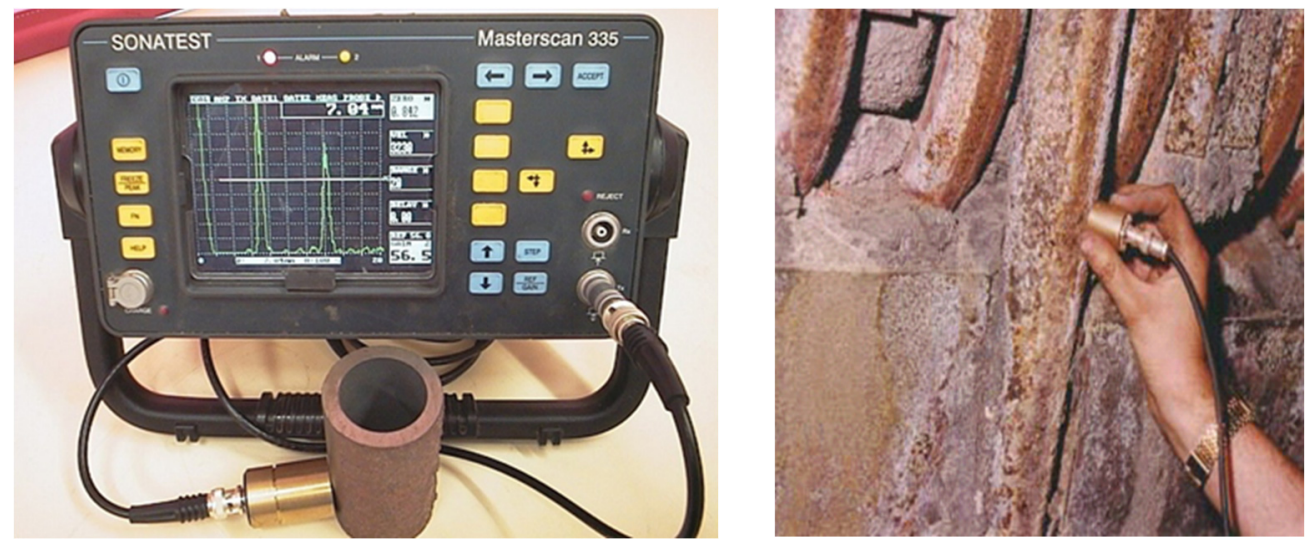

Fig. 1. EMAT transducer coupled with a popular standard UT instrument MS335 (left) and the manual EMAT thickness measurement performed on boiler tubes (right)

These experiments have shown that the accuracy of this technology is appropriate and it was proven by comparison to conventional ultrasonics was established by numerous laboratory and field evaluation in USA and UK.

\section{Design of climbing robot}

Taking in account that this EMAT technology can be used for Remaining Life Assessment in boilers it was necessary to develop device which will allow to deliver this instrumentation to the inspection field. The climbing robot was designed for examination of the thickness of water-walls tubes. It was developed by considering a moving vertical carriage that is driven by pulley and cables to move vertically along the boiler tubes Figure 2 . This device could be easily moved into boiler area and it has moving vertical carriage which can carry a sensor fixture where an ultrasonic thickness gauge, model Olympus 38DL or SONATEST is mounted. A linear DC motor and an electromagnetic solenoid are used to move the thickness gauge sensor horizontally in order to attach the gauge sensor to the boiler tube Figure 3.

In order to examine the tube thickness, some procedures are identified, and a software program was developed to control the flow of the processes that need to be accomplished by the climbing robot. The developed program is able to handle the procedure to record the thickness of the tube at different vertical positions that are separated by a certain vertical interval. In order to achieve 
precise motions of the vertical carriage and horizontal linear DC motor, closed-loop control and management strategies are designed, and these strategies are implemented at the developed robot model software.

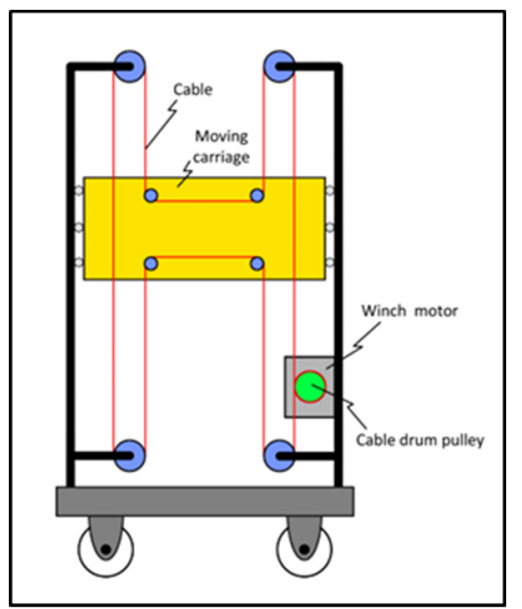

Fig. 2. Conceptual design of the climbing robot

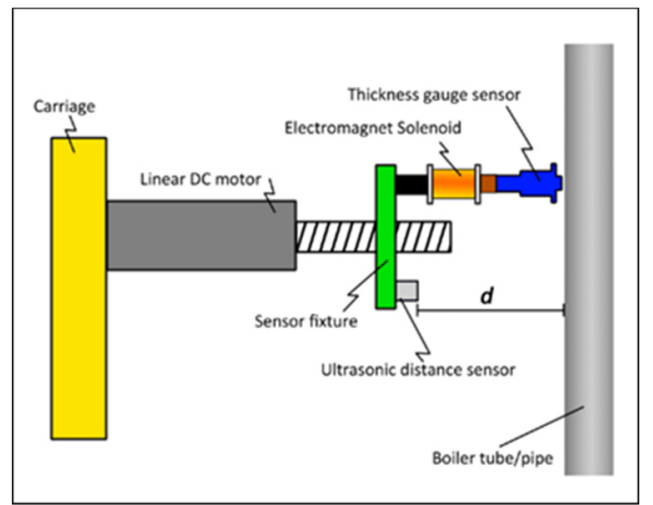

Fig. 3. Mechanism for delivery of the thickness gauge sensor to the tube surface

\section{Conclusion}

Represented here EMAT technology is used for Remaining Life Assessment of boiler tubes to prevent tube ruptures. There are two factors contributing to the tube failure: first one is erosion and corrosion and another one is overheating. Developed method is able to identify these critical points. Laboratory experiments have shown that off-shelf ultrasonic equipment can be used for boiler tubes inspection. Robotic system was designed to make process of water-wall thickness inspection easy and possibly automated.

\section{References}

[1] Bergander M., Pechacek R. Advancements in EMAT technology for boiler tube inspection. Proceedings of ASNT Fall Conference, Indianapolis, 2000, p. 63-72.

[2] Bergander M., Levesque L., Hryn W. EMAT thickness measurement for tubes in coal fired boilers. Proceedings of ASNT Fall Conference, Columbus, 2001, p. 33-57.

[3] Bergander M., Bohatec K., Snajberk J. Poznatky z provozni kontroly trubek prumyslovych zarizeni metodou magnetickych rozptylovych toku (Lessons from the operational inspection of the industrial wire pipes by the magnetic diffuse method). NDT Welding Bulletin, Prague, Czech Republic, Vol. 3, 2001, p. 83-91, (in Polish).

[4] Bergander M. EMAT thickness measurement for tubes in coal fired boilers. Proceedings of the 9th International Energy Conference "Energex", Cracow, Poland, 2002, p. 31-38.

[5] Lee K., Nelligan T. The Use of Magnetostrictive EMAT Transducers on Oxide Scaled Boiler Tubes. Internal Communication by Panametrics - NDT. A Business of R/D Tech Instruments, Inc., Waltham, Massachusetts, USA, 2005, p. 327.

[6] Maxfield B. W., Hulbert J. K. Electromagnetic acoustic-wave transducers (EMATs): their operation and mode patterns. Proceedings 10th Symposium on Non-Destructive Evaluation, San Antonio, Texas, 1975, p. 44-62.

[7] Kapayeva S., Bergander M., Vakhguelt A. Ultrasonic and EMAT - important tools to analyze a combined effect of multiple damage mechanisms in boiler tubes. Proceedings of ASNT Conference on Ultrasonics for Nondestructive Testing, Foxwoods, CT, 2016, p. 2-9. 